\title{
Two transcripts from the rotund region of Drosophila show similar positional specificities in imaginal disc tissues
}

\author{
Magali Agnel, Stephen Kerridge, Christine Vola, and Ruth Griffin-Shea ${ }^{1}$ \\ Laboratoire de Génétique et Biologie Cellulaires, Centre National de la Recherche Scientifique Case 907, 13288 Marseille \\ Cedex 9, France
}

The rotund $(\mathrm{rn})$ mutation in Drosophila is unique in that its phenotype is limited to the deletion of specific distal parts, though not the extremities, of all adult appendages. We have cloned the $r n$ gene, located at cytogenetic position $84 \mathrm{D} 3,4$, by chromosomal walking. The functional $\mathrm{rn}$ unit, defined genetically by the localization of 13 noncomplementing $m$ alleles, covers $\sim 50 \mathrm{~kb}$ of DNA. Despite different developmental profiles, two transcript size classes $(1.7$ and $5.3 \mathrm{~kb})$ from this region show an indistinguishable pattern of spatial expression in the imaginal discs at the white pupa stage. There is a high correlation between the specificity of the mutant phenotype and the accumulation of transcripts in the presumptive distal regions of the cuticleforming epithelial cells of the affected discs; it is, in fact, the first gene reported whose expression is localized with respect to the proximo distal-forming axis. For both transcripts, we have also found, uniquely in the wing disc, expression limited to the anterior region of the mesodermally derived adepithelial cells, which contribute to the muscles of the thorax.

[Key Words: Drosophila; appendage morphogenesis; rotund gene; cloning; spatial expression; imaginal disc]

Received March 17, 1988; revised version accepted October 12, 1988.

The imaginal discs of Drosophila melanogaster are the primordia of the adult cuticular structures of the head, thorax, genitalia, and analia. The discs form as invaginations of the ectoderm from cells set aside at the blastoderm stage. They grow during the larval stages and then evaginate and differentiate during pupation. Each disc gives rise to a specific part of the adult. Of the $19 \mathrm{ima}$ ginal discs, 14 give rise to structures that we consider appendages on the basis of their morphology: the wings, legs, halteres, antennae, and the proboscis. Several lines of evidence suggest that the mechanisms of pattern formation in these discs are similar. Their fate maps at the third-instar larval stage show that they are organized according to a concentric plan, the center of the disc giving rise to the distal tip of the appendage and the more peripheral parts to progressively more proximal structures. (For a review of disc development, see Bryant 1978). Finally, the combined results from studies of cell sorting (Garcia-Bellido 1966; Tobler 1966), disc regeneration (Haynie 1982), and several homeotic mutants (Postlethwait and Schneiderman 1971) suggest that the same signals are used in all these discs to specify a cell's relative position, a conclusion consistent with Wolpert's theory of positional information $(1969,1971)$.

The segmentation of the embryo of Drosophila is established by a stepwise process that subdivides the anteroposterior axis into segmental units within which

${ }^{1}$ Corresponding author. pattern is subsequently formed (Scott and O'Farrell 1986). In the discs, both the polar coordinate (French et al. 1976) and secondary embryonic field (Meinhardt 1983) models propose that pattern is ultimately elaborated along the proximo-distal axis. Genetic evidence supporting this hypothesis is provided by the decapentaplegic (dpp) (Spencer et al. 1982) and wingless (wg) (Baker 1988) hypomorphic mutations. Mutations in the disk region of the $d p p$ gene cause deletions in the distalforming regions of at least 15 of the discs; the extent of the region affected is dependent upon the allele. The appendages of $w g$ flies are also affected in large distal regions, but the alterations are more variable, including deletions, duplications, and transformations into more proximal parts.

Another gene required for pattern formation along the proximo-distal axis of the appendages is rotund $(r n)$ (Glass 1929, as referenced in Lindsley and Grell 1968; Waddington 1973; Cavener et al. 1986; Held et al. 1986; Kerridge and Thomas-Cavallin 1988). The $r n$ alleles delete a limited distal region, which seems similar in all appendages. In the leg, for example, the tarsus is much reduced and not segmented. The absence of structures is correlated with abnormal cell death in the corresponding region of the imaginal discs. The mutant adults also present decreased viability and mobility and a much reduced fertility which is germ line independent. Clonal analysis experiments indicate that the $r n$ gene is autonomous in the regions affected by $r n$ mutations and that, at a minimum, its function is required after the third-in- 
star larval stage (Kerridge and Thomas-Cavallin 1988). The $r n$ gene, unlike $d p p$ and $w g$, does not seem to play a fundamental role in early development as no phenotype is visible in mutant embryos.

In this paper we describe the generation of new $r n$ alleles, the cloning of sequences from this gene, and the characterization of the temporal and spatial expression of two of its transcripts.

\section{Results}

\section{The genetics of $\mathrm{m}$}

Cavener et al. (1986) have localized the rn gene to the right arm of the third chromosome in chromomere
84D3-4. No lethal complementation group has been found in this region or its vicinity, extending from $84 \mathrm{C} 8$ D1 to 84D3-5. A number of $r n$ alleles, mostly X-ray induced, have been described previously (Table 1A). We have generated additional alleles in two F1 mutagenesis screens, using ethylmethylsulfonate (EMS) and 1,3-diepoxybutadiene (DEB) as the mutagens. They were screened on the basis of the noncomplementation of two weak hypomorphic alleles, $r n^{4}$ and $r n^{8}$, which proved to be relatively fertile over a deletion of the 84D3-4 region. Six EMS-, and eight DEB-, induced alleles were isolated as balanced stocks.

We have 28 recessive $r n$ alleles in total (cf. Table 1). One, $m n^{\text {Dipr }}$, is also associated with a dominant pheno-

Table 1. List of $\mathrm{m}$ mutations

\begin{tabular}{|c|c|c|c|c|}
\hline Allele & Mutagen & Cytology & Comments & Reference \\
\hline \multicolumn{5}{|c|}{ A. Alleles without parental chromosome } \\
\hline$r n^{1}$ & $\mathrm{X}$-ray & $\begin{array}{l}\mathrm{T}(2 ; 3) 40-41 ; 80-81 \\
\text { plus } \operatorname{In}(3 \mathrm{R}) 81 ; 84 \mathrm{D} 3,4\end{array}$ & & 1,2 \\
\hline$r n^{3}$ & $\mathrm{X}$-ray & deletion $84 \mathrm{D} 3,4$ & & 3 \\
\hline $\mathrm{rn}^{4}$ (or F76) & EMS & normal & $\mathrm{roe}^{-} \mathrm{Scr}^{-}$ & 4 \\
\hline$m n^{5}$ & $\mathrm{X}$-ray & deletion $84 \mathrm{D} 3,4$ & & 5 \\
\hline$r n^{6}$ & $\mathrm{X}$-ray & normal & $\begin{array}{l}\text { found associated } \\
\text { with } T(Y ; 3) A 82\end{array}$ & 6,7 \\
\hline$D f(3 R) S c x^{W+R X 4}$ & $\mathrm{X}$-ray & $\mathrm{Df}(3 \mathrm{R}) 84 \mathrm{~B} ; 84 \mathrm{D} 3,4$ & ANT-C- roe $^{-}$ & 8 \\
\hline$D f(3 R) A n t p^{R I P}$ & $X$-ray & $\mathrm{Df}(3 \mathrm{R}) 84 \mathrm{~B} ; 84 \mathrm{D} 3,4$ & ANT-C,- roe $^{-}$ & 2 \\
\hline$D f(3 R) d s x^{M a s+R 29}$ & $\mathrm{X}$-ray & Df(3R)/84D2,3;84F8-10 & roe $^{-}, \mathrm{dsx}^{-}$ & 4,11 \\
\hline$D f(3 R) d s X^{M a s+R 2}$ & $\mathrm{X}$-ray & $\mathrm{Df}|3 \mathrm{R}| 84 \mathrm{~B}-\mathrm{C} ; 84 \mathrm{E} 1,2$ & $\mathrm{roe}^{-}, \mathrm{ds} \mathbf{x}^{-}$ & 4,11 \\
\hline$D f(3 R) d s x^{M a s+R 10}$ & $\mathrm{X}$-ray & $\mathrm{Df}(3 \mathrm{R}) 84 \mathrm{D} 3,4 ; 84 \mathrm{~F} 2,3$ & dsx- & 4,11 \\
\hline \multicolumn{5}{|c|}{ B. Alleles with parental chromosome } \\
\hline$r n^{7}$ & EMS & normal & $\mathrm{roe}^{-}$ & 7 \\
\hline$r n^{8}$ & EMS & normal & $\mathrm{roe}^{-}$ & 7 \\
\hline$r n^{10}$ & EMS & normal & $\mathrm{roe}^{-}$ & 7 \\
\hline$r n^{11}$ & EMS & normal & & 7 \\
\hline$r n^{14}$ & EMS & normal & & 7 \\
\hline$r n^{15}$ & EMS & normal & & 7 \\
\hline$m n^{16}$ & DEB & normal & $\mathrm{roe}^{-}$ & 7 \\
\hline$r n^{17}$ & DEB & $\mathrm{Df}(3 \mathrm{R} / 84 \mathrm{~B}-\mathrm{C} ; 84 \mathrm{D} 9-12$ & $\mathrm{roe}^{-}$ & 7 \\
\hline$m^{18}$ & DEB & normal & $\mathrm{roe}^{-}$ & 7 \\
\hline $\mathrm{rn}^{19}$ & DEB & deletion $84 \mathrm{D} 3,4$ & & 7 \\
\hline$m^{20}$ & DEB & deletion 84D3,4 & roe $^{-}$ & 7 \\
\hline$r n^{21}$ & DEB & normal & $\mathrm{roe}^{-}$ & 7 \\
\hline $\mathrm{m}^{22}$ & DEB & $\mathrm{Df}(3 \mathrm{R}) 84 \mathrm{~B}-\mathrm{C} ; 84 \mathrm{D} 9,10$ & $\mathrm{roe}^{-}$ & 7 \\
\hline$r n^{23}$ & DEB & normal & $\mathrm{roe}^{-}$ & 7 \\
\hline$r n^{\text {roeX } 49}$ & X-ray & normal & $\mathrm{roe}^{-}$ & 9 \\
\hline$r n^{X T 130}$ & $X$-ray & $\operatorname{In}(3 R) 80-81 ; 84 D 3,4$ & & 9 \\
\hline$m^{\text {Dipr }}$ & $X$-ray & $\operatorname{In}(3 \mathrm{R}), 84 \mathrm{D} 3,4 ; 84 \mathrm{~F} 6-11$ & & 10 \\
\hline \multirow[t]{2}{*}{$m n^{D i p r+R 1}$} & $\mathrm{X}$-ray & $\operatorname{In}(3 \mathrm{R}) 84 \mathrm{D} 3,4 ; 84 \mathrm{~F} 6-11$ & & 10 \\
\hline & & plus $\mathrm{Df}(3 \mathrm{R}) 84 \mathrm{~F}$ and $84 \mathrm{D}$ & & \\
\hline$m n^{D i p r+R 2}$ & $\mathrm{X}$-ray & plus $\mathrm{Df}(3 \mathrm{R} / 84 \mathrm{~F}$ and $84 \mathrm{D}$ & & 10 \\
\hline$r n^{D i p r+R 7}$ & $\mathrm{X}$-ray & plus Df(3R) $84 \mathrm{~F}$ and $84 \mathrm{D}$ & & 10 \\
\hline$r n^{D i p r+R 9}$ & $\mathrm{X}$-ray & plus $\mathrm{Df}(3 \mathrm{R}) 84 \mathrm{~F}$ and $84 \mathrm{D}$ & & 10 \\
\hline$m n^{D i p r+R 5}$ & $\mathrm{X}$-ray & $\operatorname{In}(3 \mathrm{R}) 84 \mathrm{D} 3,4 ; 84 \mathrm{~F} 6-11$ & & 10 \\
\hline$T(3: X) F C 8$ & $\mathrm{X}$-ray & $\mathrm{T}(3: \mathrm{X}) 84 \mathrm{D} 4,5-85 \mathrm{C}, \mathrm{D} ; 20$ & & 12 \\
\hline
\end{tabular}

All mutants in B were induced on a red $e^{11}$ (Ref. 1 ) chromosome, except $r n^{11}$ and $r n^{\text {Dipr }}$, which were induced on a $m w h$ iv st red $e^{11} c a$ (Ref. 1) chromosome, and $r n^{\text {roeX49 }}$ and $r n^{X T 130}$, which were induced on a st $e^{11}$ (Ref. 1) chromosome.

1. Lindsley and Grell (1968); 2. Duncan and Kaufman (1975); 3. A. Hannah-Alava (unpubl.); 4. Cavener et al. (1986); 5. J.P.W. Williams (unpubl.); 6. Lindsley et al. (1972); 7. S. Kerridge (unpubl.); 8. Hazelrigg and Kaufman (1983); 9. G. Jürgens (unpubl.); 10. Kerridge (1981); 11. B. Baker (unpubl.); 12. Lehmann and Nüsslein-Volhard (1987). 
type (Kerridge 1981). Twelve of these alleles, including some that were EMS-induced (cf. Table 1), also affect roughened-eye (roe; e.g., Cavener et al. 1986), the next complementation group proximal to $r n$. None of the alleles complement in transheterozygotes, thus defining $r n$ as a single genetic unit.

\section{Chromosomal walk through the rn locus}

We jumped from the Antennapedia (Antp) complex at $84 \mathrm{~B} 1-2$ to the region $84 \mathrm{D} 3-4$, taking advantage of the $\mathrm{rn}^{-}$ deficiency strain $D f(3 R) S c x^{W+R x 4}$ (Hazelrigg and Kaufman 1983), which juxtaposes previously cloned DNA sequences in the Antp region (Scott et al. 1983) to 84D3-4. Specifically, a recombinant DNA bank was pre-

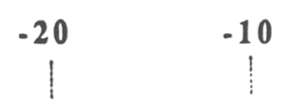

b)

c)

d)

e)

ก)

a)

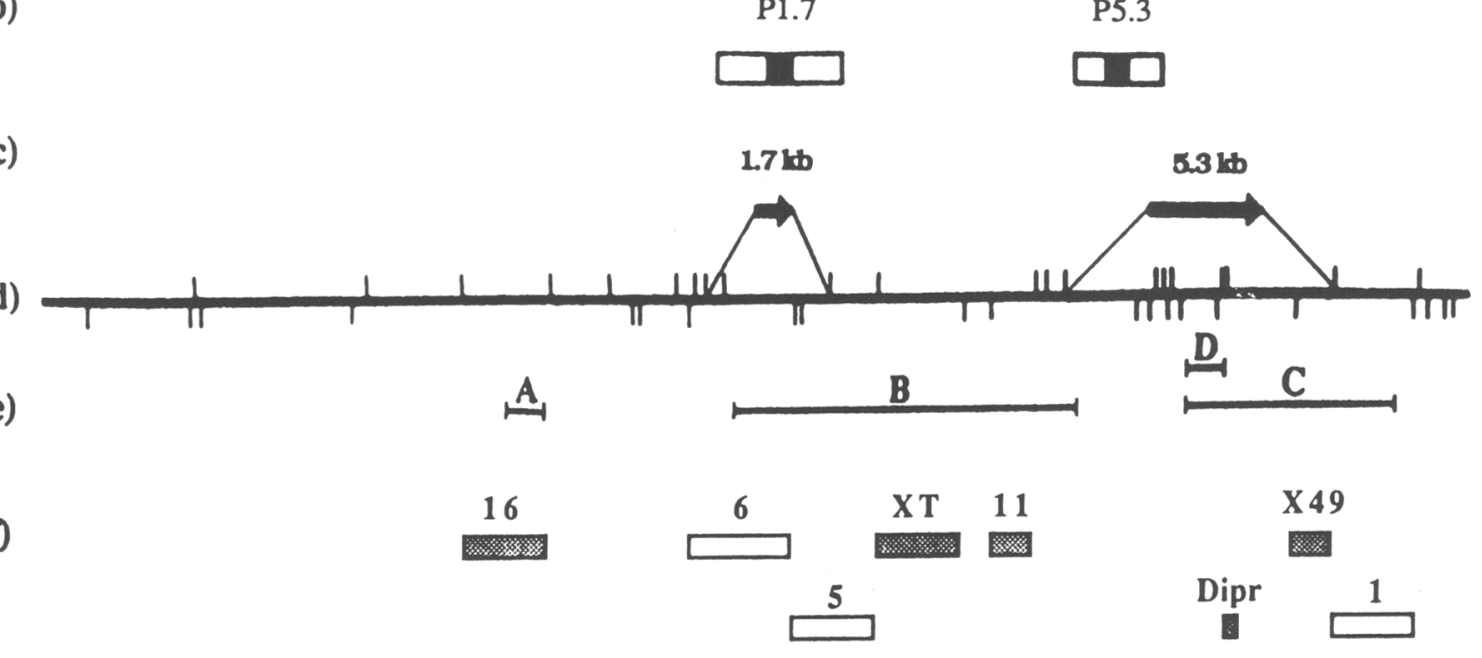

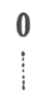

pared from this strain and screened with a clone from the Antp complex containing the sequence located at the breakpoint. Several clones were isolated that carried sequences from both sides of the deletion, as shown by their hybridization to polytene bands 84B1-2 and 84D3-4 (R. Griffin-Shea and S. Kerridge, unpubl.). We isolated a sequence restricted to the latter region from one of these fusion phages and used it as a probe to begin a chromosomal walk (Bender et al. 1983) in the Lauer-Maniatis/ Canton S library, which was continued distally in the EMBL4/Oregon $\mathrm{R}$ library. We have isolated overlapping clones from the chromosomal region 84D3-4, as shown by hybridization on polytene chromosomes (R. GriffinShea and S. Kerridge, unpubl.). They represent $70 \mathrm{~kb}$ of genomic DNA, the physical map of which is shown in

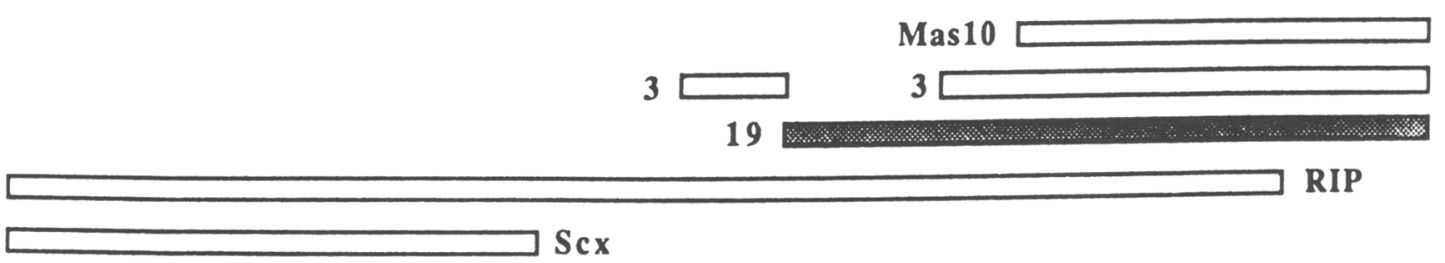

Figure 1. Genetic and transcriptional map of the $r$ region. $(a)$ Map distances, given in kilobases, are based on a value of zero given to the entry point of the walk, the distal breakpoint of $D f(3 R) S c x^{W+R X}{ }^{4} .(b)$ cDNA clones: The position of the open boxes delimits the genomic fragments with which the cDNA insert sequences hybridize; the black boxes represent only the length, and not the exact position, of the cDNA insert sequences. (c) Transcript size classes: The extents of the black boxes represent the lengths in kilobases of the transcript classes. Arrowheads indicate the direction of transcription. The lines extending from the transcript classes to the physical map show the limits of the EcoRI restriction fragments that hybridize with these transcript classes. (d) Physical map: The cloned genomic DNA is shown as a continuous line with vertical bars representing the recognition sites of endonuclease restriction enzymes EcoRI (above the line) and HindIII (below the line). (e) Probes used in the experiments and presented in the subsequent figures. (A) 1.8-kb EcoRI end fragment, -3.9 to -2.1 ; (B) 18-kb recombinant phage insert, +6.8 to 24.8 ; (C) 11.9 -kb recombinant phage insert, +30.1 to +41.9 ; (D) 2.3-kb EcoRI end fragment, +30.1 to +32.4 . $(f)$ Mutations, fully described in Table 1 , are indicated by their superscripts, in the case of the $m$ alleles, or by a three-letter code, in the case of deficiencies whose alternate breakpoints were first identified in other loci. The boxes represent segments of DNA whose restriction fragment size has been altered mutationally: Filled boxes represent mutations for which the parental chromosomes were tested; clear boxes, those for which control chromosomes were not available. Their limits indicate the smallest genomic fragment in which a change was noted and are not meant to detail the nature of mutation, except for the large deletions Mas10, 19, RIP, and Scx. The mutation $\mathrm{m}^{3}$ showed a compound pattern, with a change in one of the proximal fragments being separated by an apparently normal stretch of DNA from a substantial deletion of distal material. Deletion breakpoints are resolved only to the nearest restriction enzyme site ( \pm 500 bases). 
Figure 1d. By in situ hybridization on polytene chromosomes, we have localized the $t R N A^{\text {Valsb }}$ gene as distal to this region (R. Griffin-Shea and S. Kerridge, unpubl.); in so doing, we have ruled out the possibility proposed by Cavener et al. (1986) that lesions in this gene could represent the roe phenotype, as the roe gene is known to be proximal to the $r n$ locus.

\section{Molecular localization of the $\mathrm{rn}$ mutations}

All available alleles were used to define the $r n$ gene at the molecular level. Recombinant phages containing DNA covering the entire cloned region were used systematically as probes to Southern blots from EcoRI and HindIII digests of genomic DNA from parental and mutant strains. We used homozygous or hemizygous $r n$ mutants to prevent possible confusion by DNA from balancer chromosomes. Nineteen mutations showed alterations of the restriction enzyme patterns of the cloned region. In the case of the mutations for which we do not possess the parental strain (Table 1A; Fig. lf, open boxes), we cannot rule out the possibility that modifications of the pattern are due to polymorphisms.

Five of the eight DEB-induced alleles show detectable alterations. The proximal $r n^{16}$ mutation shows the most limited change (Fig. 2a); it deletes about $1 \mathrm{~kb}$ of a single EcoRI fragment of $4.4 \mathrm{~kb}$, located at -6.5 to -2.1 . (All coordinates cited are in kilobases, as marked in Fig. 1.) The $r n^{19}$ mutation deletes the sequences distal to +12.3 (Fig. 2b), and mutations $m n^{17}, m n^{20}$, and $m n^{22}$ remove the entire cloned region (M. Agnel and S. Kerridge, unpubl.). Of the EMS-induced alleles, infrequently detected by this method we have mapped one, $r n^{11}$; it affects the HindIII-EcoRI fragment of coordinates +20.5 to +22.8 (M. Agnel and S. Kerridge, unpubl.). Finally, all X-rayinduced mutations were found in the cloned region, except one, $T(3 ; X) F C 8$. We know by in situ hybridization to mutant polytene chromosomes that its breakpoint lies distal to the cloned region (S. Kerridge, unpubl.). Figure 2c shows the localization of the proximal breakpoint of one of the $\mathrm{X}$-ray-induced mutations, the inversion $r n^{\text {Dipr }}$ (Kerridge 1981), to the 4.1-kb HindIII fragment $(+32.1$ to +36.2$)$. This is supported by EcoRI digestion of the same mutant DNA in which this breakpoint is further delimited to a junction fragment of $0.6 \mathrm{~kb}$ (data not shown).

The molecular locations of the mutant breakpoints are summarized in Figure If. Taken as a whole, the $m$ mutations define a functional unit of at least $50 \mathrm{~kb}$ from coordinates -6.5 to $+44 \mathrm{~kb}$.

\section{Transcriptional analysis of the $\mathrm{m}$ functional unit}

Clonal analysis experiments have shown the $\mathrm{rn}^{+}$function is necessary after the third-instar larval stage (S. Kerridge, unpubl.). We searched for cDNA clones in the early pupal bank of L. Kauvar (Poole et al. 1985), using as probes all EcoRI genomic fragments of length $>1 \mathrm{~kb}$ from the $m$ functional unit. We isolated two cDNA clones, P1.7 and P5.3, with corresponding insert sizes of 1.3 and $7.7 \mathrm{~kb}$, (Fig. $1 \mathrm{~b}$ ).

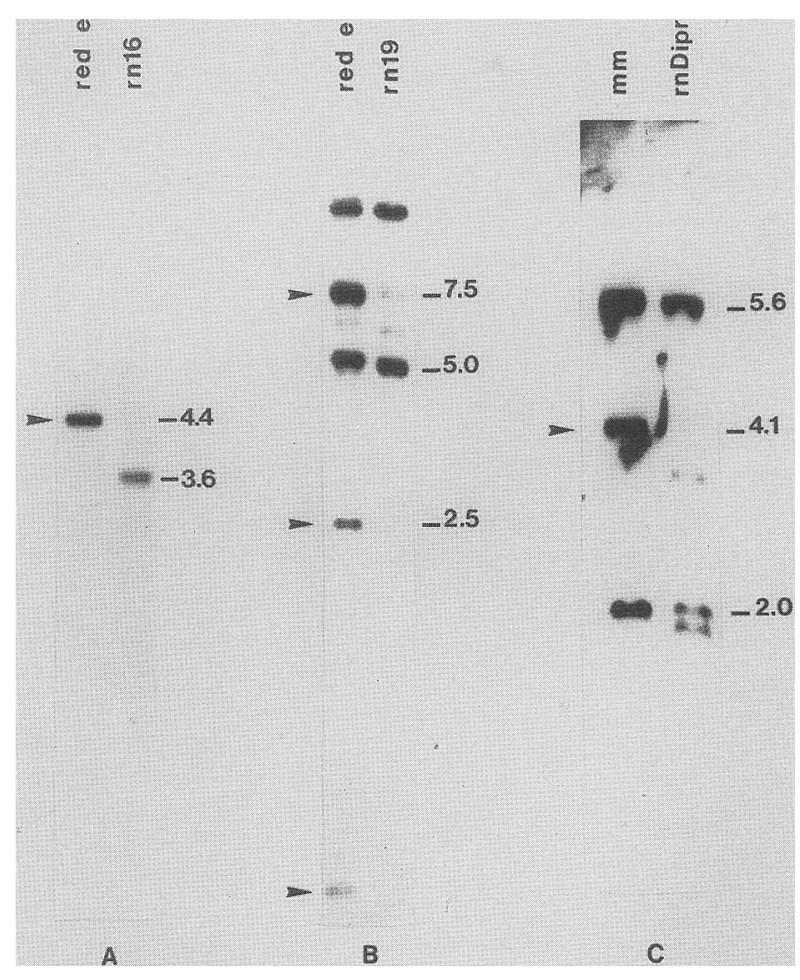

Figure 2. Molecular characterization of three $r n$ mutations. Genomic DNAs from control parental chromosomes are shown in the left track of each panel. The arrowheads point to the wild-type fragments modified by the mutation. The size of the fragments is indicated in kilobases; and the coordinates are given according to Fig. 1. (A) Parental genotype: red e/red $e_{\text {; }}$ mutant genotype: $r n^{16}$ red e/Df(3R)ds $x^{\text {Mas }+R 29} \mathrm{Dp}(3: 3) D 5$ red; enzyme: EcoRI; probe A, Fig. le. The 4.4-kb wild-type EcoRI fragment (arrowhead, -6.5 to -2.1 ) is reduced in the mutant to a 3.5 -kb fragment. No other abnormal fragment is detectable in the mutant. $(B)$ Parental genotype: red e/red $e_{\text {; mutant geno- }}$ type: $r n^{19}$ red e/Df(3R)dsx ${ }^{\text {Mas + R29 }} D p(3: 3) D 5$ red; enzyme: EcoRI; probe B, Fig. le. The bands of $7.5 \mathrm{~kb}$ and $2.5 \mathrm{~kb}$ are absent; that of $5.0 \mathrm{~kb}$ seems normal. The topmost band represents undigested DNA, variably present in these preparations. The two weak bands of 7.5 and $6.5 \mathrm{~kb}$ are due to hybridization with homologous sequences elsewhere in the genome (M. Agnel and S. Kerridge, unpubl.). All more distal sequences are missing (M. Agnel and S. Kerridge, unpubl.). (C) Parental genotype: $\mathrm{mm} \mathrm{Ma}$ -

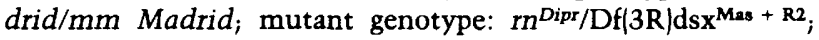
enzyme: HindIII; probe C, Fig. le. The 4.1-kb HindIII fragment $(+32.1$ to $+36.2 \mathrm{~kb})$ is absent, and two new bands are visible in the mutant ( 3.0 and $1.8 \mathrm{~kb}$ ). No other abnormality is detectable in the region.

Northern analyses were carried out by hybridizing the same genomic fragments to poly $|\mathrm{A}|^{+}$RNA from different developmental stages, ranging from embryogenesis to late pupation. For ease of discussion, we will refer to the RNA in each band as a 'transcript,' though several different RNA species of similar sizes may be present. Only two transcripts expressed during late larval and pupal stages were detected, and these correspond to the two cDNA clones. A $5.3-\mathrm{kb}$ transcript is detected by the P5.3 cDNA insert and the genomic fragments from +23.8 to +34.4 (Fig. 1d). It accumulates steadily from the embryonic stage to the end of pupation 


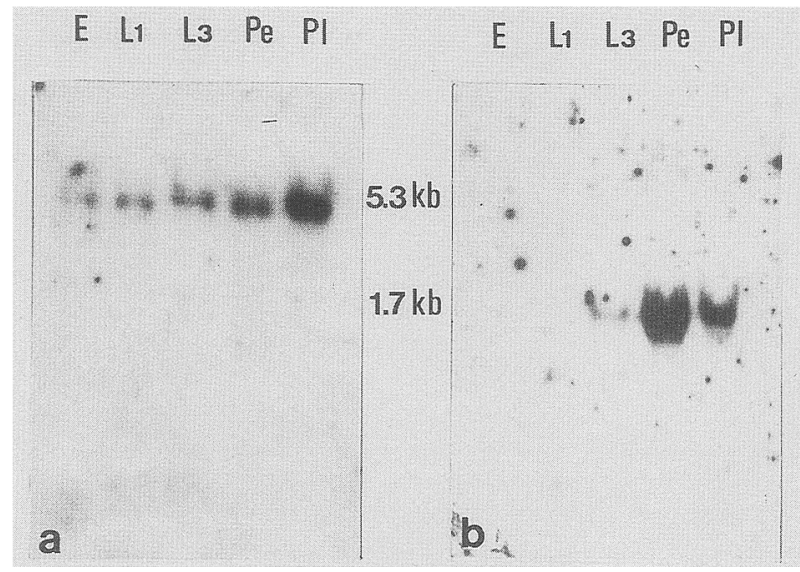

Figure 3. Developmental pattern of the transcripts of the $r n$ locus. In each track, $5 \mu \mathrm{g}$ of poly $\mid A)^{+}$RNA of the indicated stages are present. Blots were hybridized with: $(a) 2.3-\mathrm{kb}$ genomic fragment (probe D, Fig. $1 \mathrm{e}) ;(b)$ the P1.7 cDNA insert (Fig. lb). Stages: 0- to 12-hr embryos (E); first-instar larvae (L1); mounting late third-instar larvae (L3); Pupae 5.5-7 days AEL (Pe); pupae 7-10 days AEL (Pl).

(Fig. 3a). A second transcript of $1.7 \mathrm{~kb}$ hybridizes with the P1.7 cDNA insert and the fragments located between +6.3 and +12.0 (Fig. 1d). It is undetectable during embryogenesis and the first-instar larval stage and only weakly expressed at the end of the third-instar larval stage. It reaches a peak during the first 2 days of pupation, diminishing somewhat by the end of this stage (Fig. 3b).

Subsequent experiments with sense and antisense RNA probes (C. Vola, unpubl.) demonstrated that both sequences are transcribed in the same proximal-to-distal direction, as indicated in Figure 1c. Neither the hybridization on Northern blots nor cross-hybridization experiments involving the cDNA inserts and the genomic fragments gave any evidence of shared sequences between the two transcripts. Finally, although their precise structure has not been studied, sequencing data from the P1.7 cDNA insert (M. Agnel, unpubl.) and analysis of the genomic region encoding the $5.3-\mathrm{kb}$ transcript suggest that both transcripts possess introns (C. Vola, unpubl.).

\section{Positional specificity of expression of the $5.3-\mathrm{kb}$ transcript}

The spatial expression of the $5.3-\mathrm{kb}$ transcript was studied by RNA in situ hybridization experiments on frozen sections of white pupae $(0-2 \mathrm{hr}$ after pupariation). The negative control was provided by a strain $\left[D f(3 R) r n^{20} / D p(3: 3) D 5 D f(3 R) d s X^{\text {Mas }+R 29}\right]$ lacking DNA corresponding to the cloned region. We used a $2.3-\mathrm{kb}$ genomic fragment $(+30.2$ to +32.5$)$ as probe (probe $D$, Fig. le), as it had provided the most intense signal in Northern analyses.

A representative result is shown in Figure $4 a-c$. There are distinct patches of exposed grains visible in the darkfield image (Fig. 4c), which are concentrated in the distal-forming parts of the imaginal disc (Fig. 4b). This is more clearly demonstrated in Figure 4a, which presents the results of a computer-aided superposition of the exposed grains in Figure 4c onto the structures present in the light-field view in Figure $4 \mathrm{~b}$. The compound image thus generated shows that expression is limited to the distal-forming parts of the wing $(\mathrm{wd})$ and haltere $(\mathrm{h})$ discs. In the compound eye-antennal disc $(e, a)$ expression is restricted to only the distal-forming parts of the antennal disc (a). In regard to the mouthparts, there is no expression in the cibarial discs (cl), which give rise to the clypeolabrum in the adult, a structure connecting the proboscis to the head proper. However, there is a clearly-defined expression in the labial disc, limited to a precise band in the distal-forming region (Fig. $5 \mathrm{a}, \mathrm{b}$ ), that gives rise to the pseudotracheae. This transcript is also expressed in the distal-forming parts of the three pairs of leg discs, though with less intensity in the second and third leg discs than in any other disc (R. Griffin-Shea, unpubl.).

There is also an expression in an anterior subset of the adepithelial cells of the wing disc (Fig. $4 \mathrm{a}-\mathrm{c}$ ). These cells are apparently derived from the mesoderm (Shatoury and Waddington 1957; Brower et al. 1981; Vijayraghavan and Pinto 1985) and contribute to the adult musculature (Poodry and Schneiderman 1970; Ursprung et al. 1972; Reed et al. 1975; Lawrence 1982). The precise location of expression was confirmed by computer-aided superposition analysis, (R. Griffin-Shea, J.C. Fontecilla-Camps, and C. Cambillaud, unpubl.) as well as in higher magnifications. This expression is disc specific: the adepithelial cells, though present in all discs, were found to be marked only in the wing disc.

Finally, the $5.3-\mathrm{kb}$ transcript is detected in a thin stripe of tissue in the genital disc (Fig. 6a,b) in the region giving rise to the internal ducts (Bryant and Hsei 1977; Littlefield and Bryant 1979|.

\section{Similarity of positional specificity of expression of the 1.7-kb transcript}

When we used the P1.7 cDNA insert as a probe in similar in situ hybridization experiments, we found a tight correspondence between the expression of the two transcripts, extending even to the precise levels of tissue, disc, and position. The only difference may be one of degree, with the P1.7 insert, prepared under identical conditions, giving a consistently weaker signal. This is illustrated by several images that we have juxtaposed to those from the 5.3-kb transcript. Note, for example, the similar expression of the P1.7-related transcript shown in Figure $4 d-f$. Expression is again apparent in the distal-forming parts of the wing (wd) and antenna (a), with no grains detectable in the eye area (e). The lower portion of this same view is more ventral; expression is no longer visible in the antennal tissue, but a faint expression can be seen in the distal-forming part of the third leg disc (1). As for the previous transcript, expression is also visible in the same subset of cells in the adepithelial cell territory (c) of the wing disc. Perhaps most striking is the similarity of the expression in the genital disc (Fig. 6c,d); expression is again restricted to a thin, anteriorly located stripe.

In fact, for all imaginal disc tissues, the results from a 
Agnel et al.
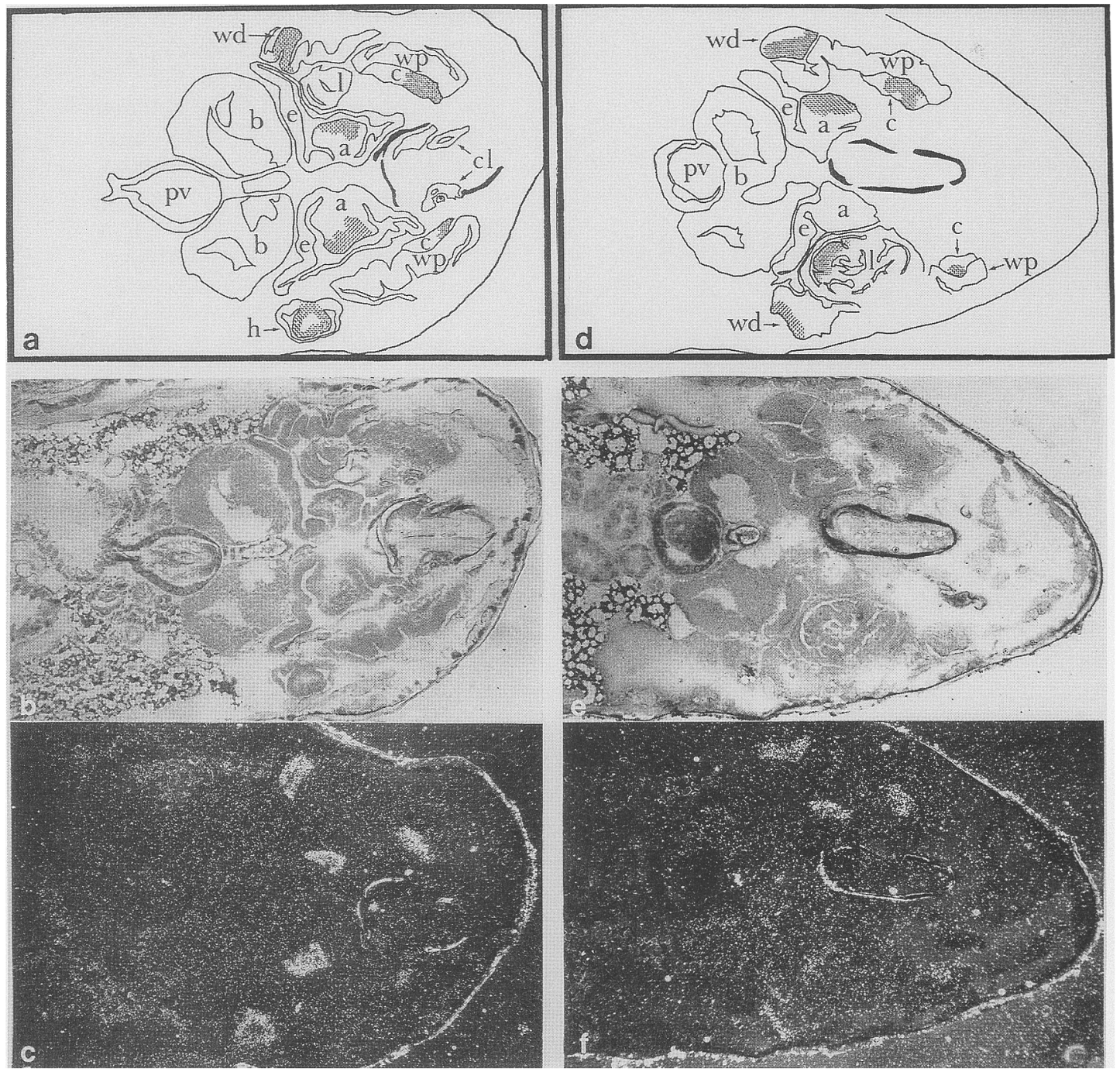

Figure 4. Localization of $m$ transcripts in tissue sections of the head regions of white pupae. $(a, d)$ Computer-aided representations of the sections in bright-field illumination in $b$ and $e$, respectively, incorporating as shaded areas the hybridization shown in the corresponding dark-field micrographs, $c$ and $f .|a, d\rangle$ : Black filled outlines represent the mouth armature; $|a|$ antennal disc; $(b \mid$ brain; $\langle c|$ adepithelial cells; $(c l)$ cibarial discs; $(h)$ haltere disc; $(I) 3^{\circ}$ leg disc; $(p v)$ proventriculus; $(w d)$ distal-forming region of the wing disc; $(w p)$ proximal-forming region of the wing disc. As shown by hybridization to the null mutant $\left[D f(3 R) \mathrm{rn}^{20} / D p(3: 3) D 5 D f(3 R) d s x^{+M a s}+R 29\right]$, there is nonspecific binding to the cuticle. Probes: $\{a, b, c)$ 2.3-kb genomic fragment (probe D, Fig. le $)_{;}(d, e, f)$ Pl.7 cDNA insert $($ Fig. $1 b)$. Magnification, $64 \times$.

series of such experiments lead to the conclusion that the spatial specificity of the expression of the two transcripts is indistinguishable.

\section{Discussion}

Evidence from molecular genetic analyses indicates that we have cloned sequences from the $r n$ gene. We have generated and characterized 15 new rn alleles, confirming and extending the earlier results of Cavener et al. (1986) that all $m$ mutations belong to the same complementation group. Physical mapping of the breakpoints of $13 \mathrm{~m}$ alleles within DNA cloned from 84D3-4 shows the gene to extend over $50 \mathrm{~kb}$. Its length may be even larger, as the breakpoint of one cytogenetically visible mutation maps distally to the cloned region. How- ever, its low penetrance $10 \%$ versus $100 \%$ for all other alleles) suggests that it may be outside the gene itself. The large size of the gene precludes its direct identification by conventional in vivo transformation assays (Rubin and Spradling 1982).

We examined the region for transcripts showing a correlation between the specificity of their expression and the mutant phenotype. We found two, of 1.7 and $5.3 \mathrm{~kb}$, as potentially coding for the $m$ function. Although differing in their developmental profile of expression, both are present in the third-instar larval and pupal stages, the minimum periods for $r n$ function as defined by clonal analysis and the larval mutant phenotype. Moreover, their positional specificities of expression in the discs are indistinguishable and in good correlation with the mutant phenotype: the transcripts are detected in 

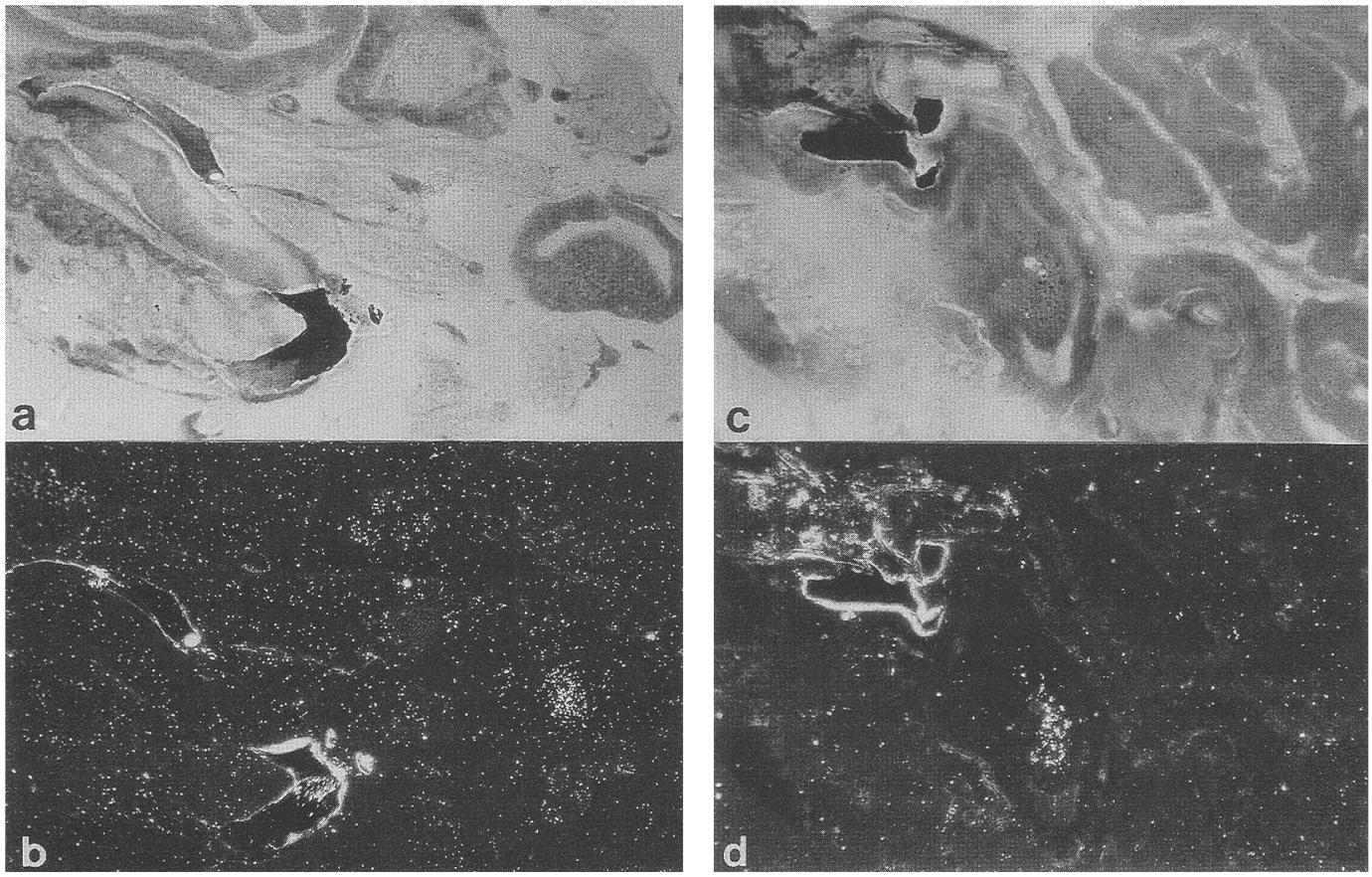

Figure 5. Expression of $m$ transcripts in the labial discs of white pupae. $(a, c)$ Sagittal sections (dorsal surface lowermost) of the mouth region of white pupae viewed in bright-field illumination. Hybridization to the right of the birefringent mouth parts in $b$ and $d$ is localized to a limited region of the labial disc. Probes $(a, b) 2.3-\mathrm{kb}$ genomic fragment $(\mathrm{D}, \mathrm{Fig} \text {. le })_{;}(c, d)$ P1.7 cDNA insert $($ Fig. $1 \mathrm{~b})$. Magnification, $150 \times(a, b) ; 192 \times(c, d)$.
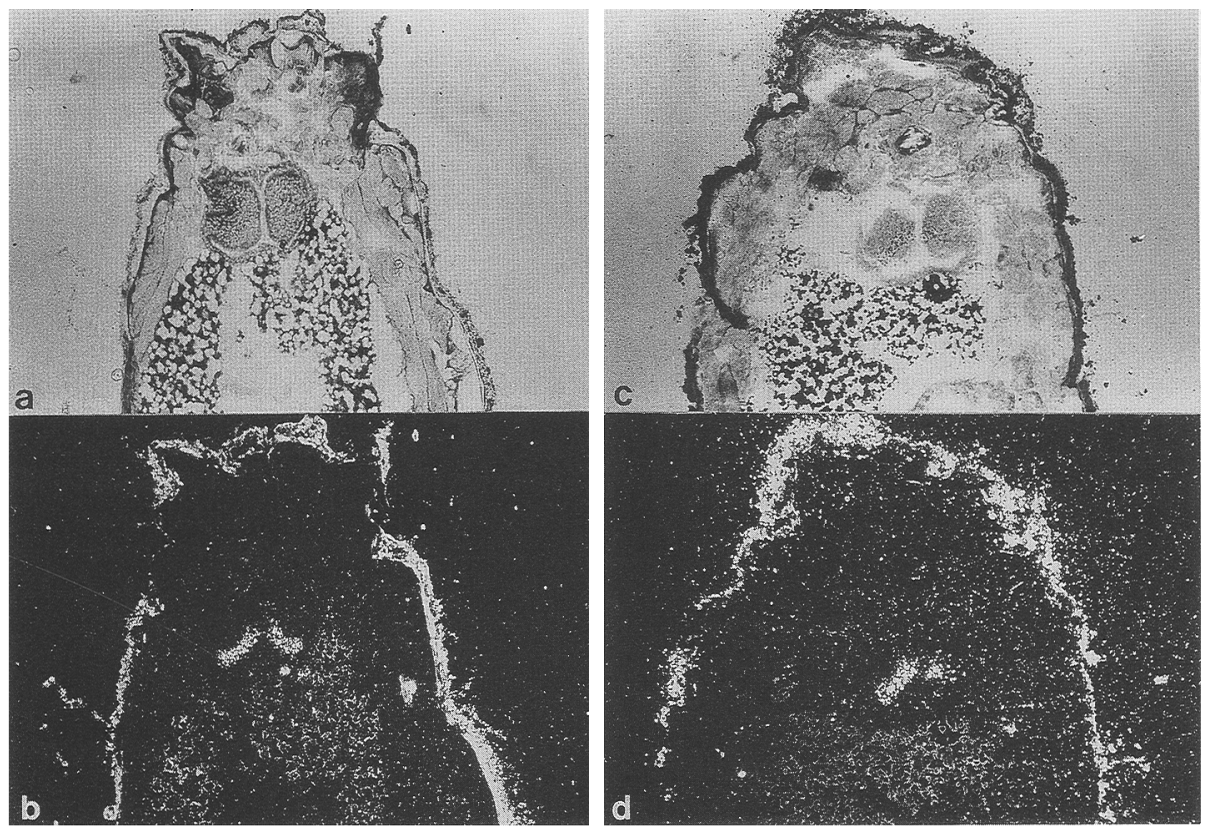

Figure 6. Localization of the expression of the transcripts of the $m$ locus to an anterior stripe in the genital discs of white pupae. $(a, c)$ Frontal sections of the posterior regions of white pupae. Ovoid structures are the genital discs. Stripes of hybridization in $b$ and $d$ map to anterior portions of the genital discs. Probes: $(a, b) 2.3-\mathrm{kb}$ genomic fragment (D, Fig. le); $(c, d)$ P1.7 cDNA insert (Fig. 1b). Magnification, $57.5 \times$ 
those discs affected by a lack of $r n$ function and are limited to the presumptive distal regions altered by the $m$ mutations.

The identification of two transcripts within the $r n$ gene was not expected from the genetic data, which defined a single function. A similar situation has been reported for three sex-determination genes, Sex-lethal (Maine et al. 1985a,b), doublesex (Baker and Wolfner 1988), and transformer (Butler et al. 1986; McKeown et al. 1987). For these loci, only a single transcript class seems to be functional. To determine the biological function of the $r n$ transcripts, we have undertaken the study of their expression in $r n$ mutants, as well as the characterization of their products.

A question remains as to the functional significance of rn transcription in parts of discs giving rise to internal tissues. The expression of both transcripts in a thin stripe of tissue in the genital discs, in the region of the presumptive genital ducts, may be related to the sterility of $r n$ flies: Examination of these structures by optical microscopic techniques in several mutants reveals the seminal receptacles to be significantly shorter than in wild-type flies, suggesting a morphogenetic function for the $r n$ gene in the genital disc. (M. Agnel, unpubl.). Likewise, the fact that $r n$ mutants do not fly may be linked to transcript accumulation in the adepithelial cells of the wing disc; these cells contribute to the formation of the thoracic muscles, including those governing flight. Higher resolution studies will be necessary to define precisely the structures affected in the mutant tissues.

The characteristic feature of the two transcripts is their similar restricted positional specificity of expression. In the morphologically homogeneous adepithelial cell territory, the accumulation of $r n$ transcripts reveals the existence of two cell types: an anterior population that expresses the $r n$ gene, and a posterior one, that does not. It may be possible to use this expression specifically to mark the anterior cells during their development and determine whether $r n$ expression is correlated with a difference in cell fate. In the epithelium of the appendage-forming discs, $r n$ provides the first example of the restriction of transcript expression along the proximodistal axis. This expression provides experimental support for Meinhardt's proposal that the proximo-distal axis of the antenna and leg discs is subdivided progressively into secondary fields during pattern formation (1983). It suggests further that this process occurs in all appendage-forming discs, whether their derivatives are segmented or not.

\section{Methods}

\section{Drosophila stocks and mutagenesis}

The $r n$ mutations used are listed in Table 1. Other mutations not referenced in Table 1 can be found in Lindsley and Grell (1968).

New alleles of $r n$ were induced with EMS or DEB in two separate $F_{1}$ screens. Males homozygous for red $e$ or mm Madrid (Kerridge and Morata 1982) were fed overnight on $12.5 \mathrm{mM}$ EMS or $10 \mathrm{mM}$ DEB in $1 \%$ sucrose. They were then crossed with either $r n^{4} / T M 3$ or $r n^{8} / T M 3$ females. Flies with a $r n$ phenotype in the $F_{1}$ generation were isolated and crossed to flies of the genotype $r n^{3} e / T M 1, r e d$. The new $r n$ alleles were isolated on the basis of their red phenotype over TM1,red. Complementation tests between all possible combinations of $m$ alleles were performed.

\section{Phage DNA preparations}

Small-scale DNA preparations and endonuclease enzyme restriction digestions were performed as in Maniatis et al. (1982). For the large-scale DNA preparations, we have followed the procedure of Scott et al. (1983), except that phage were purified through a glycerol gradient as in Garber et al. (1983).

\section{Lambda library from mutant flies}

The $\lambda$ EMBL4 phage (Frischauf et al. 1983) was used to clone Sau3A partial digests of genomic DNA, as described by Kam et al. (1980). Protocols were taken from Kuner et al. (1985) for monitoring the extent of digestion and for $\lambda$ arm preparation. Vector DNA was ligated to $14-$ to $22-\mathrm{kb}$ genomic DNA and packaged in vitro (Maniatis et al. 1982). Plating and screening of inserts were as in Scott et al. (1983).

\section{Screening of libraries}

The genomic Canton S DNA library prepared by Lauer and Maniatis (Maniatis et al. 1978) and the Oregon R DNA library from Frischauf et al. (1983) were used for the chromosomal walk. cDNA libraries were prepared by L. Kauvar in $\lambda \mathrm{gt} 10$ from pupae (P) 5-7.5 days after egg laying (AEL) and pupae (Q) 7-9 days AEL (Poole et al. 1985).

In each case, we have followed the screening protocol described by Benton and Davis (1977). Prehybridization and hybridization were performed at $65^{\circ} \mathrm{C}$ overnight using $5 \times 10^{6}$ $\mathrm{dpm} / \mathrm{ml}$ of a nick-translated ${ }^{32}$-labeled DNA fragment $\left(1 \times 10^{8}\right.$ to $\left.2 \times 10^{8} \mathrm{cpm} / \mu \mathrm{g}\right)$. The last washing was performed in $0.1 \times \mathrm{SSC}$ at $65^{\circ} \mathrm{C}$ for $10 \mathrm{~min}$. Autoradiography on Fuji X-ray films was carried out at $-80^{\circ} \mathrm{C}$ with a Dupont Lightning-plus intensifying screen.

\section{Preparation of probes}

Whole phage were used as probes in Southern blots, and either genomic fragments or cDNA inserts digested by EcoRI endonuclease restriction enzyme were used in Northern and in situ hybridization analyses. In all cases, endonuclease restriction fragments were purified electrophoretically from agarose gels (Maniatis et al. 1982) and 80-200 ng of purified DNA sequence was labeled radioactively using random oligonucleotides as primers (Feinberg and Vogelstein 1983). Labeling with [32 P]dCTP and [ $\left.{ }^{32} \mathrm{P}\right] \mathrm{dTTP}$ (3000 Ci/mmole; Amersham) was to sp. act. of $1 \times 10^{9} \mathrm{dpm} / \mu \mathrm{g}$. For tritium labeling, three nucleotides were used (dATP, dCTP, and dTTP; 30-100 Ci/mmole; Amersham) to produce probes with sp. act. of $2 \times 10^{8}$ to $4 \times 10^{8} \mathrm{dpm} / \mu \mathrm{g}$.

\section{Drosophila DNA preparations and Southern blot analysis}

DNA from 20 flies was prepared according to Junakovic (1980) and then digested by EcoRI or HindIII restriction endonuclease enzymes (Boehringer). The DNA was fractionated in $0.7 \%$ agarose gels and blotted onto Hybond $\mathrm{N}$ nylon membranes (Amersham). Prehybridization, hybridization, and stringent washings were carried out as described by Amersham. 


\section{RNA preparations}

Flies at different stages of development $\left(25^{\circ} \mathrm{C}\right)$ from the $D . m e$ lanogaster Oregon R strain were collected and frozen in liquid nitrogen. The frozen samples were ground to a powder under liquid nitrogen and then homogenized in $4 \mathrm{M}$ guanidium thiocyanate solution. The RNA was pelleted through a $5.7 \mathrm{M} \mathrm{CsCl}$ cushion and purified, all as described in Chirgwin et al. (1979). Poly $(\mathrm{A})^{+}$RNA was obtained by two passages through oligo (dT)-cellulose (Aviv and Leder 1972).

\section{Northern blot analysis of RNA}

Poly $(\mathrm{A})^{+}$RNA samples were electrophoresed in formaldehydecontaining agarose gels essentially as described in Maniatis et al. (1982). Each lane contained $5 \mu \mathrm{g}$ of poly(A) ${ }^{+}$RNA. Escherichia coli $16 \mathrm{~S}$ and 23S rRNA and 1-kb ladder DNA (BRL) were used as molecular weight markers. Transfer of RNA from gel to nitrocellulose filter and hybridization of the blot were as described by Thomas (1980), with the following modifications: The hybridization medium contained $5 \mathrm{ng} / \mathrm{ml}$ of oligolabeled ${ }^{32}$-labeled probe, $2 \%$ polyadenylic and polycytidilic acids (Sigma), and $10 \%$ dextran sulfate (Pharmacia). The last stringent wash was done at $55^{\circ} \mathrm{C}$ in $0.1 \times$ SSC, $0.1 \%$ SDS. Autoradiography was carried out as described above.

\section{In situ hybridization to frozen sections of white pupae}

White pupae were collected and sectioned as in Akam (1983). Section pretreatment and reduction of probe size (50-200 bases) was as in Akam and Carlson (1985). Hybridization, washing, and exposure procedures were taken from Hafen et al. (1983), with the following exceptions: Pretreatment included acetylation (Hayashi et al. 1978); $40 \mu \mathrm{l}$ of hybridization medium was used per slide with $22 \times 32$-mm coverslips; each labeled probe preparation was distributed over 16 slides; coverslips were not sealed; after exposure, slides were fixed in Ilford Hypam fixer $+7.2 \%$ (vol/vol) Ilford Rapid Hardener. Photomicrographs were made with Panatomic-X film.

Specificity of hybridization was checked initially by probing RNase-treated sections. In addition, in every experiment, nonspecific binding was determined by comparing signals from wild-type pupae with those obtained from hybridization of the same probes with the deficiency mutant $\left[D f(3 R) \mathrm{rn}^{20} / D p(3: 3)\right.$ D5 $D f(3 R) d s x^{M a s}+R 29$, which removes the totality of the cloned $m$ locus. Nonspecific binding to the cuticle was observed in all experiments; variably, we also observed nonspecific binding of these probes to the cuticle, the armature of the mouth, the tracheae, the interior of the gut, and the region of the salivary glands. In all cases, slides were developed after 1 month for the $2.3-\mathrm{kb}$ probe, and after 4 months, for the P1.7 probe. However, these exposure times are not directly comparable; for the experiments presented here, the quantity of P1.7 insert sequence labeled was reduced deliberately to $\sim 80 \mathrm{ng}$, thereby possibly affecting subsequent hybridization kinetics in an effort to reduce a persistent background problem.

\section{Computer analysis of in situ hybridization results}

The structures present in the light-field view of Figure $4 \mathrm{~b}$, as well as the exposed grains from the corresponding dark-field image in Figure $4 c$, were traced independently of one another onto the same coordinate system by means of a digitalizing tablet. The resulting images were visualized and superimposed on a Picture Systems II (Evans and Sutherland, Salt Lake City, Utah). The program was written and made available by Dr. Juan C. Fontecilla-Camps.

\section{Acknowledgments}

Special thanks are due to Matt Scott, who offered the advice and materials to get us started in our walk. We appreciate the help of numerous people, who sent us libraries, clones, and mutants, including Tom Maniatis, Larry Kauvar, Hans Lehrach, Juan Modolell, Gordon Tener, Michael Rosbash, Ian Dawson, Gurd Jürgens, Tom Kaufman, Bruce Baker, Ruth Lehmann, and Eliane Mohier. For stimulating discussion, we are indebted to Juan Modolell, Gary Struhl, Phil Ingham, Welcome Bender, Michael Wilcox, Bill Gelbart and his colleagues, Philip Leder and his colleagues, and especially to Fotis Kafatos and his colleagues, who provided cordial hospitality as well. We thank our colleagues in Marseilles for their active interest, particularly Mario Houde for sharing experimental expertise; Michele Thomas-Cavallin and Bernard Kniebehler for advice on the preparation and interpretation of frozen sections; Roland Rosset for his support and critical reading of the manuscript; Yves Thouveny for use of his equipment; and Juan FontecillaCamps for his computer graphics program and comments on the manuscript. This work was supported, in part, by a grant (AIP 1137) from the Centre National de la Recherche Scientifique.

\section{References}

Akam, M.E. 1983. The location of Ultrabithorax transcripts in Drosophila tissue sections. EMBO J. 2: 2075-2084.

Akam, M.E. and J.R. Carlson. 1985. The detection of Jonah gene transcripts in Drosophila by in situ hybridization. EMBO J. 4: $155-161$.

Aviv, H. and P. Leder. 1972. Purification of the biologically active globin messenger RNA by chromatography on oligothymidilic acid-cellulose. Proc. Natl. Acad. Sci. 69: 1408-1412.

Baker, N.E. 1988. Transcription of the segment-polarity gene wingless in the imaginal discs of Drosophila, and the phenotype of a pupal-lethal wg mutation. Development 102: 489497.

Baker, B.S. and M.F. Wolfner. 1988. A molecular analysis of doublesex, a bifunctional gene that controls both male and female sexual differentiation in Drosophila melanogaster. Genes Dev. 2: 477-489.

Bender, W., P. Spierer, and D.S. Hogness. 1983. Chromosomal walking and jumping to isolate DNA from the Ace and rosy loci and the Bithorax Complex in Drosophila melanogaster. I. Mol. Biol. 168: 17-33.

Benton, W.D. and R.W. Davis. 1977. Screening $\lambda$ gt recombinant clones by hybridization to single plaques in situ. Science 196: 180-192.

Brower, D., P. Lawrence, and M. Wilcox. 1981. Clonal analysis of the undifferentiated wing disk of Drosophila. Dev. Biol. 86: 448-455.

Bryant, P.J. 1978. Pattern formation in imaginal disks. In The genetics and biology of Drosophila (ed. M. Ashburner and T.R.F. Wright), vol. 2C, pp. 230-325. Academic Press, New York.

Bryant, P.J. and B.W. Hsei. 1977. Pattern formation in asymmetrical and symmetrical imaginal discs of Drosophila melanogaster. Am. Zool. 17: 595-611.

Butler, B., V. Pirotta, I. Irminger-Finger, and R. Nöthiger. 1986. The sex-determining gene tra of Drosophila: Molecular cloning and transformation studies. EMBO I. 5: 3607-3613.

Cavener, D.A., D.C. Otteson, and T.C. Kaufman. 1986. A rehabilitation of the genetic map of the 84B-D region in Drosophila melanogaster. Genetics 114: 111-123.

Chirgwin, J.M., A.E. Przybyla, R.J. MacDonald, and W.J. Rutter. 1979. Isolation of biologically active ribonucleic acid from 
sources enriched in ribonuclease. Biochemistry 18: 52945299.

Duncan, I.W. and T.C. Kaufman. 1975. Cytogenetic analysis of chromosome 3 in Drosophila melanogaster: Mapping of the proximal portion of the right arm. Genetics 80: 733-752.

Feinberg, A.P. and B. Vogelstein. 1983. A technique for radiolabeling DNA restriction endonuclease fragments to high specific activity. Anal. Biochem. 132: 6-13.

French, V., P.J. Bryant, and S.V. Bryant. 1976. Pattern regulation in epimorphic fields. Science 193: 969-980.

Frischauf, A.M., H. Lehrach, A. Poustka, and N. Murray. 1983. Lambda replacement vector carrying polylinker sequences. J. Mol. Biol. 170: 827-842.

Garber, R.L., A. Kuroiwa, and W.J. Gehring. 1983. Genomic and cDNA clones of the homeotic locus Antennapedia in Drosophila. EMBO J. 2: 2027-2036.

Garcia-Bellido, A. 1966. Pattern reconstruction by dissociated imaginal disk cells of Drosophila melanogaster. Dev. Biol. 14: 278-306.

Hafen, E., M. Levine, R.L. Garber, and W.J. Gehring. 1983. An improved in situ hybridization method for the detection of cellular RNAs in Drosophila tissue sections and its application for localizing transcripts of the homeotic Antennapedia gene complex. EMBO /. 2: 617-623.

Hayashi, S., J.C. Gillam, A.D. Delaney, and M. Tener. 1978. Acetylation of chromosome squashes of Drosophila melanogaster decreases the background in autoradiographs from hybridizations with ${ }^{125}$ I-labeled RNA. I. Histochem. Cytochem 26: 677-679.

Haynie, J.L. 1982. Homologies of positional information in thoracic imaginal discs of Drosophila melanogaster. Wilhelm Roux's Arch. Dev. Biol. 191: 293-300.

Hazelrigg, T.I. and T.C. Kaufman. 1983. Revertants of dominant mutations associated with the Antennapedia gene complex of Drosophila melanogaster: Cytology and genetics. Genetics 105: 581-600.

Held, L.I., C.M. Duarte, and K. Derakhshanian. 1986. Extra tarsal joints and abnormal cuticular polarities in various mutants of Drosophila melanogaster. Wilhelm Roux's Arch. Dev. Biol. 195: 145-157.

Junakovic, N. 1980. Variability in the molecular organization of the 5S RNA genes among strains of Drosophila melanogaster. Nucleic Acids Res. 8: 3611-3622.

Karn, J., S. Brenner, L. Barnett, and G. Cesarini. 1980. Novel bacteriophage lambda cloning vector. Proc. Natl. Acad. Sci. 77: 5172-5176.

Kerridge, S. 1981. Distal into proximal (Dipr): A homeotic mutation of Drosophila melanogaster. Mol. Gen. Genet. 184: 519-525.

Kerridge, S. and G. Mortata. 1982. Developmental effects of some newly induced Ultrabithorax alleles of Drosophila. I. Embryol. Exp. Morphol. 68: 211-234.

Kerridge, S. and M. Thomas-Cavallin. 1988. Appendage morphogenesis in Drosophila: A developmental study of the rotund $(r n)$ gene. Wilhelm Roux's Arch. Dev. Biol 197: 19-26.

Kuner, J.M., M. Nakanishi, Z. Ali, B. Drees, E. Gustavson, J. Theis, L. Kauvar, T. Kornberg, and P.H. O'Farrell. 1985. Molecular cloning of engrailed: A gene involved in the development of pattern in Drosophila melanogaster. Cell 42: 309316.

Lawrence, P.A. 1982. Cell lineage of the thoracic muscles of Drosophila. Cell 29: 493-503.

Lehmann, R. and C. Nüsslein-Volhard. 1987. hunchback: A gene required for segmentation of an anterior and posterior region of the Drosophila embryo. Dev. Biol. 119: 402-417.

Lindsley, D.L. and E.H. Grell. 1968. Genetic variations of Dro- sophila melanogaster. Carnegie Inst. Washington Publ. 627. Lindsely, D.L., L. Sandler, B.S. Baker, A.T.C. Carpenter, R.E. Denell, J.C. Hall, P.A. Jacobs, G.L. Gabor Miklos, B.K. Davis, R.C. Gethmann, R.W. Hardy, A. Hessler, S.M. Miller, H. Nozawa, D.M. Parry, and M. Gould-Somero. 1972. Segmental aneuploidy and the genetic gross structure of the Drosophila genome. Genetics 71: 157-184.

Littlefield, C.L. and P.J. Bryant. 1979. Prospective fates and regulative capacities of fragments of the female genital disc of Drosophila melanogaster. Dev. Biol. 70: 127-148.

Maine, E.M., H.K. Salz, P. Schedl, and T.W. Cline. 1985a. The Sex-lethal gene of Drosophila: DNA alterations associated with sex-specific lethal mutations. Cell 43: 521-529.

1985b. Sex-lethal, a link between sex-determination and sexual differentiation in Drosophila melanogaster. Cold Spring Harbor Symp. Quant. Biol. 50: 595-604.

Maniatis, T., E.F. Fritsch, and J. Sambrook. 1982. Molecular cloning: A laboratory manual. Cold Spring Harbor Laboratory, Cold Spring Harbor, New York.

Maniatis, T., R.C. Hardison, E. Lacy, J. Lauer, C. O'Connell, D. Quon, G.K. Sim, and A. Efstratiadis. 1978. The isolation of structural genes from libraries of eukaryotic DNA. Cell 15: $687-701$.

McKeown, M., J. Belote, and B.S. Baker. 1987. A molecular analysis of transformer, a gene in Drosophila melanogaster that controls female sexual differentiation. Cell 48: 479-487.

Meinhardt, H. 1983. Cell determination boundaries as organizing regions for secondary embryonic fields. Dev. Biol 96: $375-385$

Poodry, C.A. and H.A. Schneiderman. 1970. The ultrastructure of the developing leg of Drosophila melanogaster. Wilhelm Roux's Arch. Dev. Biol. 166: 1-44.

Poole, S.J., L.M. Kauvar, B. Drees, and T. Kornberg. 1985. The engrailed locus of Drosophila: Structural analysis of an embryonic transcript. Cell 40: $37-43$

Postlethwait, J.H. and H.A. Schneiderman. 1971. Pattern formation and determination in the antenna of the homeotic mutant Antennapedia of Drosophila melanogaster. Dev. Biol. 25: 606-640.

Reed, C.T., C. Murphy, and D. Fristrom. 1975. The ultrastructure of the differentiating pupal leg of Drosophila melanogaster. Wilhelm Roux's Arch. 178: 285-302.

Rubin, G.M. and A.C. Sprading. 1982. Genetic transformation of Drosophila with transposable element vectors. Science 218: 348-353.

Scott, M.P. and P.H. O'Farrell. 1986. Spatial programming of gene expression in early Drosophila embryogenesis. Annu. Rev. Cell. Biol. 2: 49-80.

Scott, M.P., A.J. Weiner, T.I. Hazelrigg, B.A. Polisky, V. Pirrotta, F. Scalenghe, and T.C. Kaufman. 1983. The molecular organization of the Antennapedia locus of Drosophila. Cell 35: $763-776$.

Shatoury, H.H. and C.H. Waddington. 1957. Functions of lymph gland cells during the larval period in Drosophila. $J$. Embryol. Exp. Morphol. 5: 122-133.

Spencer, F.A., F.M. Hoffman, and W.M. Gelbart. 1982. Decapentaplegic: A gene complex affecting morphogenesis in Drosophila melanogaster. Cell 28: 451-461.

Thomas, P.S. 1980. Hybridization of denatured RNA and small DNA fragments transferred to nitrocellulose. Proc. Natl. Acad. Sci. 77: 5201-5205.

Tobler, H. 1966. Zellspezifische Determination und Beziehung zwischen. Proliferation und Transdetermination in Beinund Flügelprimordien von Drosophila melanogaster. $1 . \mathrm{Em}$ bryol. Exp. Morphol. 16: 609-633.

Ursprung, H., M. Conscience-Egli, D.J. Fox, and T. Walliman. 
1972. Origin of leg musculature during Drosophila metamorphosis. Proc. Natl. Acad. Sci. 69: 2812-2813.

Vijayraghavan, K. and L. Pinto. 1985. The cell lineage of the muscles of the Drosophila head. J. Embryol. Exp. Morphol. 85: 285-294.

Waddington, C.H. 1973. The morphogenesis of patterns in Drosophila. In Developmental systems: Insects (ed. S.J. Counce and C.H. Waddington), pp. 499-535. Academic Press, New York.

Wolpert, L. 1969. Positional information and spatial pattern of cellular differentiation. J. Theoret. Biol. 25: 1-47.

1971. Positional information and pattern formation. Curr. Top. Dev. Biol. 6: 183-224. 


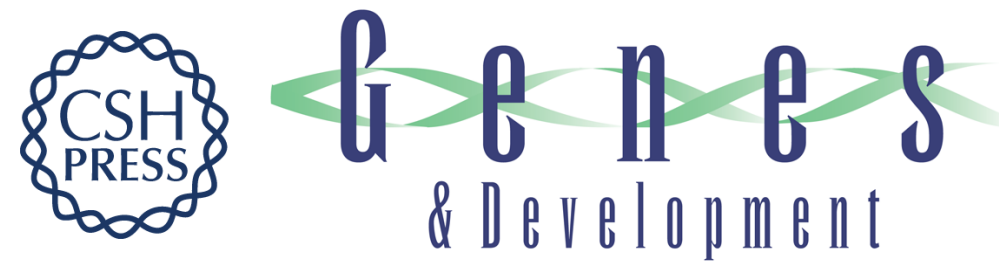

\section{Two transcripts from the rotund region of Drosophila show similar positional specificities in imaginal disc tissues.}

M Agnel, S Kerridge, C Vola, et al.

Genes Dev. 1989, 3:

Access the most recent version at doi:10.1101/gad.3.1.85

References This article cites 53 articles, 14 of which can be accessed free at:

http://genesdev.cshlp.org/content/3/1/85.full.html\#ref-list-1

License

Email Alerting

Service

Receive free email alerts when new articles cite this article - sign up in the box at the top right corner of the article or click here.

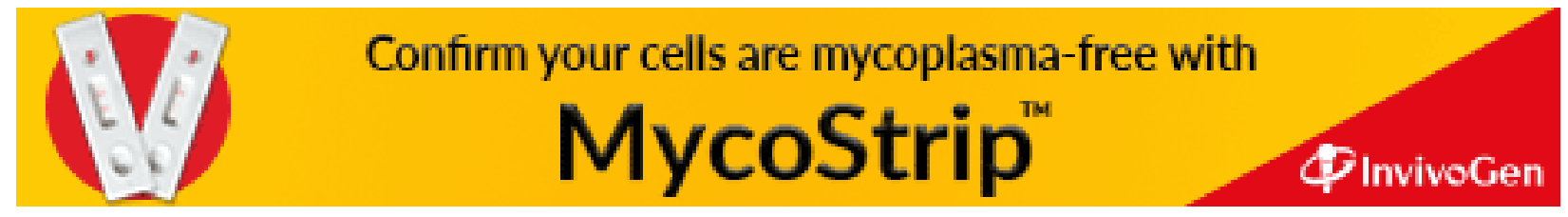

